\title{
A REFORMA CURRICULAR DO ENSINO MÉDIO NO CEPAE
}

Andréa Ferreira Delgado, Alcir Horácio da Silva, Alésio Clarete Isaac Vieira, Alexandra Almeida de Oliveira, Elisandra Filetti, Elizabete de Oliveira Pereira, Evandson Paiva Ferreira, Fernando Pereira dos Santos, Gervácio Gonçalves Martins, Kátia de Oliveira Campos, Marcello lucas, Maria José Oliveira de Faria Almeida, Marilene Barcelos Moreira, Nelson Carneiro Júnior, Paulo César Vieira de Araújo, Rejane Cirqueira Valério, Rusvênia luíza Batista Rodrigues da Silva, Wanderley Alves dos Santos*, Alessandra da Silva Carrijo**

\section{ReSUMO}

$\mathrm{O}$ artigo apresenta a nova organização curricular do ensino médio no Cepae, discutindo tanto os princípios do Projeto Político-Pedagógico da instituição quanto as proposições da Lei de Diretrizes e Bases da Educação Nacional, dos Parâmetros Curriculares Nacionais e das Diretrizes Curriculares Nacionais. Problematizam-se também as premissas pedagógicas do currículo e os significados da proposta de flexibilização, que estimulam o aluno a construir parte significativa do seu currículo ao optar por uma das grandes áreas do conhecimento (Humanas, Exatas ou Biológicas) e por um elenco diversificado de disciplinas optativas.

PalaVras-Chave: disciplinas optativas, ensino médio, flexibilização curricular, organização curricular.

\section{The high school curricular organization in Cepae}

\section{AbSTRACT}

This paper introduces the new High School curricular organization in the Centro de Ensino e Pesquisa Aplicada à Educação (Cepae), discusses the principles of the Political-Pedagogic Project of this institution, the propositions of the Lei de Diretrizes e Bases da Educação Nacional (LDB), the National Curricular Parameters and the Diretrizes Curriculares Nacionais (DCN) to High School. It also discusses the pedagogic premises of the curriculum and the meaning of the flexibility proposal, which stimulates the students to build a meaninful part of their curriculum when choosing one of the larger areas of knowledge (Human, Exact or Biological) as well as a diversified range of elective subjects.

KEY WORDS: curricular flexibility proposal, curricular organization, high school, electives subjects.

* Professores da Comissão de Implementação e Acompanhamento da Reforma Curricular do Ensino Médio do Cepae, coordenada pela professora doutora Andréa Ferreira Delgado.

E-mail: andreadelgado@uol.com.br

** Técnica em Assuntos Educacionais do Cepae. 


\section{Revista Solta a Voz, v. 16, n. 2}

\section{INTRODUÇÃO}

A reforma do ensino médio no Centro de Ensino e Pesquisa Aplicada à Educação (Cepae) configura-se em um trabalho de três anos, viabilizado por meio de comissões compostas por professores das subáreas de Artes, Biologia, Educação Física, Filosofia, Física/Química, Geografia, História, Língua Estrangeira, Língua Portuguesa, Matemática e Sociologia, desse Centro, vinculado à Universidade Federal de Goiás. A implantação gradativa começou em 2004, com a adoção da nova organização curricular para a primeira série, e trouxe novos desafios decorrentes das transformações suscitadas na rotina escolar, que envolvem desde questôes referentes à organização do tempo e do espaço escolar até complexas alterações nas práticas pedagógicas. Por isso, compreendemos que não estamos envolvidos na execução de uma proposta pronta e acabada, mas vivenciamos uma nova etapa do processo de reconstrução do projeto para o ensino médio do Cepae, que exige a participação dos professores, servidores técnico-administrativos, pais e alunos.

Nesse sentido, a Comissão de Implantação e Acompanhamento da Reforma do Ensino Médio elaborou este artigo, para apresentar e fundamentar a nova organização curricular, visando ampliar a discussão e estimular a continuidade do processo de construção da reforma proposta.

O pressuposto do nosso trabalho é o caráter político do currículo, que, longe de ser uma grade que articula disciplinas e horas, constitui o resultado de uma concepção de educação que fundamenta uma proposta pedagógica de formação humana (Kuenzer, 2002).

Por isso, a reforma curricular orienta-se pelo Projeto Político-Pedagógico do Cepae, resultado de um trabalho coletivo configurado num documento que propicia um referencial para o trabalho pedagógico realizado na primeira e segunda fases do ensino fundamental e no ensino médio. Trata-se da construção de uma "educação crítica, que analisa as relaçôes sociais vigentes e os interesses sociais em jogo", a partir da concepção de que "a práxis humana pode criar, recriar e transformar a realidade social” (Centro de Ensino e Pesquisa Aplicada à Educação, 2002, p. 10). Essa concepção de educação, portanto, associa a "apropriação e análise de saberes sistematizados historicamente" com a formação de "sujeitos ativos, críticos, solidários e democráticos" (Centro de Ensino e Pesquisa Aplicada à Educação, 2002, p. 11). 
Para a elaboração de uma proposta para o ensino médio, além do Projeto Político-Pedagógico do Cepae, consideramos os seguintes documentos: Constituição Brasileira (Art. 205 e 210); Lei de Diretrizes e Bases da Educação Nacional (LDB / Lei no 9.394/96) (Brasil, 1996, apud Brasil, 2002); Diretrizes Curriculares Nacionais para o Ensino Médio (DCNEM) do Conselho Nacional de Educação (Resolução da Câmara de Educação Básica - CEB/CNE no 3/98) (Brasil, 1998, apud Brasil, 2002); e Parâmetros Curriculares Nacionais para o Ensino Médio (PCNEM), elaborados pelo Ministério da Educação (Brasil, 2002).

\section{Ensino médio: princípios do Projeto Político-Pedagógico do Cepae OPERACIONALIZADOS NOS PLANOS DE ENSINO DAS SUBÁREAS}

De acordo com a Lei de Diretrizes e Bases da Educação (LDB), em seu artigo 22,

a educação básica tem por finalidade desenvolver o educando, assegurarlhe a formação comum indispensável para o exercício da cidadania e fornecer-lhe meios para progredir no trabalho e em estudos posteriores. (Brasil, 1996 apud Brasil, 2002)

Essa concepção de que a educação deve promover o desenvolvimento do educando, preparando-o para uma ação social consciente e crítica, orienta o Projeto Político-Pedagógico do Cepae e fundamenta o trabalho pedagógico no ensino médio.

Nesse nível, tem-se por objetivo desenvolver integralmente os adolescentes, oferecendo-lhes oportunidade de aprendizagem que os torne capazes de fazer uma leitura do momento histórico, científico e cultural em que vivem, integrando-se nele perspectiva de construção de uma sociedade mais justa. (Centro de Ensino e Pesquisa Aplicada à Educação, 2002, p. 15)

No art. 35 da LDB, são apontadas as finalidades do ensino médio, "etapa final da educação básica":

I - a consolidação e o aprofundamento dos conhecimentos adquiridos no ensino fundamental, possibilitando o prosseguimento de estudos; 
II - a preparação básica para o trabalho e a cidadania do educando, para continuar aprendendo, de modo a ser capaz de se adaptar com flexibilidade a novas condições de ocupação ou aperfeiçoamento posteriores;

III - o aprimoramento do educando como pessoa humana, incluindo a formação ética e o desenvolvimento da autonomia intelectual e do pensamento crítico;

IV - a compreensão dos fundamentos científico-tecnológicos dos processos produtivos, relacionando a teoria com a prática, no ensino de cada disciplina. (Brasil, 1996, apud Brasil, 2002)

Kuenzer (2002) destaca que a LDB determina a "unidade de orientação" para o ensino médio, que, independente da forma como se organize, deverá propiciar ao educando a formação geral, a preparação para o trabalho e o exercício da cidadania. Com essa nova identidade, segundo Cury (2002), a função formativa predomina sobre a função propedêutica e a função profissionalizante delineadas pela legislação anterior. Nesse sentido, Oliveira (2002, p. 56) afirma que

a educação geral seria considerada formação para o trabalho, capacitando os indivíduos para assumirem funções mais versáteis no processo produtivo e preparando-os para as diversas modalidades de formação continuada e treinamentos específicos que serão demandados no futuro.

De forma coerente com os princípios da LDB, consta no Projeto Político-Pedagógico do Cepae que a formação intelectual do educando, para a inserção no mundo do trabalho, é indissociável da sua preparação para a atuação autônoma e ética na vida social:

[...] nossa proposta pretende instrumentalizar o aluno não só para o mercado de trabalho, mas também para a sua participação na sociedade de maneira autônoma, solidária, consciente, ativa e crítica. (Centro de Ensino e Pesquisa Aplicada à Educação, 2002, p. 10)

Em consonância com o Projeto Político-Pedagógico e com as finalidades apontadas para o ensino médio, enfatizam-se nos Projetos de Ensino das Subáreas do Cepae as mediações entre os conteúdos específicos e o objetivo primordial de preparar o educando para o exercício da cidadania, relacionando o ensino-aprendizagem com a realidade e a experiência social dos alunos. 
A questão da cidadania constitui-se efetivamente como um dos eixos centrais da proposta pedagógica para o ensino médio no Cepae, indissociável de outro: a formação necessária para que os alunos prossigam nos estudos. Foi com essa dupla perspectiva que encaramos o desafio de exercer a autonomia pedagógica concedida às escolas pela LDB e formular uma nova proposta para o ensino médio, tal como estimulam as Diretrizes Curriculares Nacionais para o Ensino Médio, elaboradas pela Câmara de Educação Básica do Conselho Nacional de Educação (Brasil, 1998, apud Brasil, 2002, p. 82).

A reformulação curricular do ensino médio aproveita a possibilidade de flexibilização da organização da educação básica apontada na LDB para elaboração de uma proposta com “identidade própria”, tal como sugerida nas Diretrizes Curriculares, ou seja, que ouse estabelecer alternativas de construção curricular que atenda às necessidades e expectativas dos alunos e de suas famílias e do corpo docente e técnico-administrativo do Cepae.

\section{A ORGANIZAÇÃo CURRICULAR}

De acordo com o art. 26 da LDB (Brasil, 1996, apud Brasil, 2002),

os currículos do ensino fundamental e médio devem ter uma base nacional comum, a ser complementada, em cada sistema de ensino e estabelecimento escolar, por uma parte diversificada, exigida pelas características regionais e locais da sociedade, da cultura, da economia e da clientela (grifos nossos).

Com base nessa lei, a estrutura curricular do ensino médio no Cepae compõe-se de disciplinas obrigatórias, que formam o Núcleo Básico e devem ser cursadas por todos os alunos - contemplando a "base nacional comum" - , e de disciplinas acessórias, que integram "a parte flexível” do currículo, a ser construída por cada aluno - e que corresponde à "parte diversificada" proposta na LDB, tal como detalharemos a seguir.

\section{O NúCleo Básico}

O Núcleo Básico é formado por um conjunto de disciplinas obrigatórias anuais e obrigatórias semestrais. São aquelas comuns a todos os alunos e deverão ser cursadas no turno matutino em duas turmas de trinta 
alunos cada e de disciplinas obrigatórias semestrais, organizadas por nível de conhecimento (correspondem às disciplinas Língua Estrangeira: Inglês, Francês e Espanhol) (Quadro 1).

QUADRO 1. Disciplinas do Núcleo Básico e carga horária

\begin{tabular}{|l|l|}
\hline $\begin{array}{l}\text { Núcleo Básico } \\
\text { Disciplinas }\end{array}$ & Carga horária \\
\hline Matemática & 120 \\
Português & 160 \\
Física & 120 \\
Química & 120 \\
Biologia & 80 \\
História & 80 \\
Geografia & 80 \\
Artes & 40 \\
Educação Física & 40 \\
Inglês* & 80 \\
Francês $^{*}$ & 80 \\
Espanhol* $^{*}$ & 80 \\
\hline Carga horária total & $\mathbf{1 . 0 0 0}$ horas \\
\hline
\end{tabular}

Obs.: No segundo ano, acrescenta-se a disciplina Filosofia ( 80 horas) e, no terceiro ano, a disciplina Sociologia (80 horas). * Para a integralização dos estudos de Língua Estrangeira, os alunos deverão cursar a disciplina Espanhol (escolhida como obrigatória por meio de consulta à comunidade escolar) e optar por outra - Inglês ou Francês.

No Núcleo Básico contempla-se, portanto, a base nacional comum exigida no art. 26 da LDB, visto que se incluem "o estudo da língua portuguesa e da matemática, o conhecimento do mundo físico e natural e da realidade social e política” (Brasil, 1996, apud Brasil, 2002), além do ensino da arte, da educação física e de línguas estrangeiras, que também são componentes curriculares obrigatórios no ensino médio.

A proposta dos Parâmetros Curriculares Nacionais (Brasil, 2002) de organizar a base curricular nacional por áreas de conhecimento foi analisada 
e avaliada. Porém, exercendo nossa autonomia curricular, decidimos reservar essa alternativa de organização à parte flexível. Assim, mantendo uma parte do currículo estruturada em disciplinas, e outra, em áreas do conhecimento, exploramos ao máximo as possibilidades de organização pedagógica.

Acreditamos que a manutenção da organização curricular por disciplinas no Núcleo Básico é condição essencial para a composição das Áreas de Conhecimento da parte diversificada do currículo. A construção histórica de cada disciplina delineou objetos específicos de conhecimentos e produziu conceitos e representações do mundo organizadas em conjunto de saberes padronizados. Portanto, o ensino dos conteúdos curriculares de cada disciplina é condição para que o educando aproprie-se criticamente de diferentes linguagens para interpretação do mundo. Por isso, as disciplinas constituem a base epistemológica da interdisciplinaridade que fundamenta as áreas do conhecimento.

No Núcleo Básico, contemplamos as disciplinas que compõem as três áreas de conhecimento recomendadas pelos PCNEM e DCNEM: Linguagens, Códigos e suas Tecnologias; Ciências da Natureza, Matemática e suas Tecnologias; e Ciências Humanas e suas Tecnologias. Com isso, cumprimos o indicado nos PCNs: "O que é obrigatório pela LDB ou pela Resolução n ${ }^{\circ}$ 03/98 são os conhecimentos que estas disciplinas recortam e as competências e habilidades a eles relacionados" (Brasil, 2002, p. 32).

\section{A PARTE FLEXÍvel do CURRÍ́culo}

Como já vimos, a Lei de Diretrizes e Bases prevê que, para complementar a base nacional comum, os currículos do ensino fundamental e médio devem contar com uma parte diversificada, que respeite "[...] as características regionais e locais da sociedade, da cultura, da economia e da clientela” (Art. 26) (Brasil, 1996, apud Brasil, 2002, p. 44).

Nos Parâmetros Curriculares para o Ensino Médio, afirma-se que a parte diversificada do currículo deve expressar "as prioridades estabelecidas no projeto da unidade escolar e a inserção do educando na construção do seu currículo" e considerar

as possibilidades de preparação básica para o trabalho e o aprofundamento em uma disciplina ou uma área, sob forma de disciplinas, projetos ou módulos em consonância com os interesses dos alunos e da comunidade a que pertencem. (Brasil, 2002, p. 36) 
A partir desses fundamentos legais, construímos uma proposta de flexibilização do currículo, criando uma parte diversificada composta de disciplinas acessórias obrigatórias e disciplinas acessórias optativas.

\section{DisCiplinas aCesSÓRIAS OBRIGATÓRIAS}

Cada aluno vai complementar o Núcleo Básico com um conjunto de disciplinas acessórias obrigatórias que deverá cursar de acordo com sua opção por uma das Áreas de Conhecimento - Humanas, Biológicas, Exatas - visando a ampliação e o aprofundamento de conhecimentos específicos a estes campos científicos. Fundamentamo-nos na idéia de que

a escola é o espaço privilegiado para o estabelecimento de relaçôes significativas com todas as áreas do conhecimento de modo a preparar o aluno para assumir-se também como sujeito de sua história e da história da humanidade, compreendendo o papel revolucionário da ciência para a destruição das condiçôes geradoras de exclusão, as quais, frutos da práxis humana, só através dela serão superadas. (Kuenzer, 2002, p. 49)

As disciplinas acessórias obrigatórias são semestrais e cursadas em turmas formadas por no mínimo dez e no máximo trinta alunos, preferencialmente no turno vespertino (no Quadro 2 constam as disciplinas que compóem cada área de conhecimento, com suas respectivas cargas horárias).

Embora essas áreas difiram parcialmente daquelas sugeridas nos $\mathrm{Pa}-$ râmetros Curriculares Nacionais (Linguagens; Ciências da Natureza e Matemática; e Ciências Humanas), o critério de composição foi semelhante, pois fundamentou-se na

reunião daqueles conhecimentos que compartilham objetos de estudo e, portanto, mais facilmente se comunicam, criando condições para que a prática escolar se desenvolva numa perspectiva de interdisciplinaridade. (Brasil, 2002, p. 32)

As especificidades de cada disciplina são preservadas, pois a organização "por áreas não implica a desconsideração ou o esvaziamento dos conteúdos, mas a seleção e a integração dos que são válidos para o desenvolvimento pessoal e o incremento da participação social" dos educandos (Brasil, 2002, p. 32). 
QUADRO 2. Disciplinas acessórias obrigatórias

\begin{tabular}{|c|c|c|c|c|c|}
\hline $\begin{array}{l}\text { Área de } \\
\text { conhecimento }\end{array}$ & Humanas & Biológicas & & Exatas & \\
\hline $\begin{array}{l}\text { Disciplinas } \\
\text { acessórias } \\
\text { obrigatórias }\end{array}$ & $\begin{array}{l}\text { Português } 40 \mathrm{~h} \\
\text { História } 40 \mathrm{~h} \\
\text { Geografia } 40 \mathrm{~h} \\
\text { Filosofia } \\
\text { Sociologia } \\
\text { Educação Física } \\
\text { Artes } \\
\text { Línguas } \\
\text { Estrangeiras }\end{array}$ & $\begin{array}{l}\text { Biologia } \\
\text { Química } \\
\text { Matemática } \\
\text { Física }\end{array}$ & $\begin{array}{l}40 \mathrm{~h} \\
40 \mathrm{~h} \\
40 \mathrm{~h} \\
40 \mathrm{~h}\end{array}$ & $\begin{array}{l}\text { Matemática } \\
\text { Física } \\
\text { Química }\end{array}$ & $\begin{array}{l}40 \mathrm{~h} \\
40 \mathrm{~h} \\
40 \mathrm{~h}\end{array}$ \\
\hline Carga horária & $120 \mathrm{~h}^{*}$ & & $160 \mathrm{~h}$ & & $120 \mathrm{~h}$ \\
\hline
\end{tabular}

Obs.: $\mathrm{O}$ aluno poderá modificar sua opção por uma das áreas de conhecimento, no início do segundo ano. No entanto, essa nova opção implica que deverá cursar as disciplinas acessórias obrigatórias da área escolhida, ofertadas no primeiro ano. * As 120 horas da carga horária das disciplinas acessórias obrigatórias da área de Humanas devem contemplar o estudo de História, Geografia e Português, que podem promover uma articulação interdisciplinar com as demais disciplinas que compõem a área.

Além disso, conforme consta nas Diretrizes Curriculares Nacionais para o Ensino Médio, a proposta de organização por áreas de conhecimento não pressupõe um conjunto fechado ou definitivo de disciplinas. Ao contrário, a preocupação em "ampliar as possibilidades de interação não apenas entre as disciplinas nucleadas em uma área como entre as próprias áreas de nucleação" (Brasil, 1998, apud Brasil, 2002, p. 91) constitui um dos fundamentos do currículo proposto para o ensino médio.

\section{DisCIPLINAS ACESSÓRIAS OPTATIVAS}

Para integralizar a carga horária de 1.260 horas anuais, cada aluno deverá completar seu currículo escolhendo semestralmente as disciplinas acessórias optativas que deseja cursar, a partir de um conjunto de disciplinas. 
Na concepção que orienta a organização curricular, compreende-se que essas disciplinas devem estimular propostas interdisciplinares, envolvendo disciplinas da mesma área de conhecimento ou de áreas distintas visando estabelecer o diálogo constante entre as diferentes áreas do saber.

Como a carga horária das disciplinas optativas completa a parte flexível do currículo, ela varia de acordo com a carga horária estabelecida em cada área de conhecimento: Humanas - 140 horas de disciplinas acessórias optativas (120 horas de disciplinas acessórias obrigatórias); Exatas - 140 horas de disciplinas acessórias optativas (120 horas de disciplinas acessórias obrigatórias); Biológicas - 100 horas de disciplinas acessórias optativas (160 horas de disciplinas acessórias obrigatórias).

$\mathrm{Na}$ definição da parte flexível do currículo, percebe-se que o princípio que rege a nova proposta para o ensino médio é a possibilidade de cada educando construir parte significativa de seu próprio currículo optando por uma área de conhecimento e escolhendo suas disciplinas optativas.

As disciplinas acessórias obrigatórias, por um lado, "permitem aos alunos aprofundarem, desde cedo, seus conhecimentos e habilidades nas áreas em que possuem maior vocação ou talento" (Cunha, 2002, p. 115) - ou seja, naquelas áreas com as quais, ao longo da prática social e escolar, foram identificando-se. As disciplinas optativas, por outro, proporcionam a oportunidade de os alunos explorarem outras áreas, questionando e revendo continuamente suas escolhas.

Essa flexibilização do currículo e diversificação das modalidades de disciplinas

não significa apenas reconhecer que existem preferências dos alunos em face das diferenças individuais que levam alguns a gostar de artes, outros de comunicação, de humanidades, ciências exatas ou tecnologias, mas reconhecer que muitas vezes as "preferências" expressam limitaçoos de conhecimento, ou mesmo antecipada consciência de impossibilidade, em decorrência de experiências anteriores determinadas pelas condiçôes materiais de existência. (Kuenzer, 2002, p. 47)

Em outras palavras, na prática de construir seu próprio currículo, os alunos passam a ressignificar experiências, vivências e aptidões, exercitando o auto-conhecimento ao longo dos três anos do ensino médio.

A flexibilização associada à diversidade constitui a identidade do ensino médio do Cepae, pois configura uma organização curricular que 
visa efetivamente responder à heterogeneidade dos educandos e às características do meio sociocultural.

\section{AS PREMISSAS PEDAGÓGICAS DO CURRÍCULO}

A necessidade de harmonia entre o Núcleo Básico e a parte flexível, enfatizada nos documentos oficiais como condição para que o "currículo faça sentido como um todo" (Brasil, 2002, p. 98), está garantida pela organização do trabalho pedagógico do Cepae em subáreas que correspondem às disciplinas, posteriormente reunidas em áreas do conhecimento - área de Ciências Humanas e Filosofia, área de Ciências da Natureza e Matemática, e área de Comunicação.

Numa primeira instância, tal como fica configurado nos planos de ensino das subáreas para o ensino médio, o currículo é planejado pelas subáreas, considerando-se a inter-relação entre conteúdos e metodologias da disciplina anual que compõem o Núcleo Básico e das disciplinas acessórias obrigatórias e acessórias optativas ofertadas.

A composição de áreas de conhecimento, porém, exige transformações na prática escolar (Zibas, 2002), visto que a interdisciplinaridade é um dos princípios pedagógicos da estrutura curricular e requer novas formas de organização do trabalho escolar.

$\mathrm{Na}$ implantação da reforma, pretendemos que as áreas de conhecimento sejam as instâncias de proposição das disciplinas acessórias obrigatórias, pois o currículo deve ser trabalhado de forma interdisciplinar, a fim de romper com o tratamento compartimentado do conhecimento escolar. As disciplinas acessórias optativas, por sua vez, podem configurar experiências interdisciplinares entre as áreas.

Tanto nos Parâmetros Curriculares, elaborados pelo Ministério da Educação, quanto nas Diretrizes Curriculares do Conselho Nacional de Educação para o Ensino Médio, a interdisciplinaridade associa-se à contextualização dos conhecimentos como pressupostos pedagógicos da reforma curricular.

A integração dos diferentes conhecimentos pode criar condições necessárias para uma aprendizagem motivadora, na medida em que ofereça maior liberdade aos professores e alunos para a seleção de conteúdos mais diretamente relacionados aos assuntos ou problemas que dizem respeito à vida da comunidade. (Brasil, 1998, apud Brasil, 2002, p. 36) 
A análise dos Projetos de Ensino das Subáreas do Cepae demonstra que a contextualização fundamenta a seleção e o tratamento dos conteúdos. Porém, no processo de implementação da reforma, muito ainda temos a aprender sobre a operacionalização do tratamento interdisciplinar do trabalho pedagógico.

A interdisciplinaridade não pode ser imposta ao corpo docente mediante a mudança curricular. Ao contrário, conforme Nogueira (1994, p. 74), a integração interdisciplinar ocorre através de processos, através do delineamento de rumos que busquem a "aventura construtiva que é o conhecimento", potencializando a contribuição de cada ciência para o conhecimento, a compreensão e a intervenção na realidade social.

De acordo com a concepção de Etges (1995, p. 64), "a interdisciplinaridade que propomos tem sua base na própria gênese e no fundamento da própria produção do saber", pois as ações interdisciplinares, como mediadoras entre as diferentes disciplinas, fundamentam-se no princípio da diversidade e da criatividade para impelir a transposição e o deslocamento de um sistema disciplinar historicamente construído para outro, a fim de responder aos desafios postos pela complexidade do conhecimento.

Nas Diretrizes Curriculares para o Ensino Médio, apontam-se caminhos para organização de trabalhos interdisciplinares no contexto escolar:

[...] será principalmente na possibilidade de relacionar as disciplinas em atividades ou projetos de estudos, pesquisa e ação, que a interdisciplinaridade poderá ser uma prática pedagógica e didática adequada aos objetivos do ensino médio. (Brasil, 1998, apud Brasil, 2002, p. 88)

Essas ações demandam a superação de velhas práticas e posturas no modo de agir de professores e alunos no processo de ensino-aprendizagem. Segundo Menezes (1999, p. 2),

para desenvolver competências para a vida social e para o trabalho, para promover a visão de mundo, valores humanos e cultura entre todos os alunos de todos os contingentes sociais, é preciso romper com a tradição de manter os alunos em passividade, e de identificar conhecimento e cultura como uma soma de conteúdo de disciplinas estanques.

Nesse sentido, uma das possibilidades que se vislumbra com a nova estrutura curricular é a organização das disciplinas acessórias na forma de 
projetos, elaborados a partir dos princípios da interdisciplinaridade e da contextualização da aprendizagem.

\section{O ALUNO E A CONSTRUÇÃO DO PRÓPRIO CURRÍCULO: UM EXERCÍCIO DE AUTONOMIA E AUTOCONHECIMENTO}

A proposta que elaboramos para o ensino médio fundamenta-se na flexibilização da organização curricular e tem como principal característica o fato de que o aluno constrói parte significativa de seu currículo, ao realizar a opção por uma área de conhecimento e, a cada semestre, pelas disciplinas optativas que cursará.

Nosso currículo inova ao possibilitar que o aluno curse um elenco diversificado de disciplinas, planejadas em função do Projeto de Ensino das diferentes subáreas e da proposta pedagógica das áreas de conhecimento para o ensino médio, que objetivam tanto a contribuição na formação da cidadania quanto a fundamentação necessária para que o aluno prossiga seus estudos.

A ousadia com que assumimos a orientação dos PCNEMs e das DCNEMs de incentivar a inserção do educando na composição de seu próprio currículo é coerente com a proposta pedagógica configurada no Projeto Político-Pedagógico de estimular a construção de identidades autônomas, por meio de práticas educativas comprometidas com a formação ética, com o desenvolvimento do pensamento crítico e da autonomia intelectual do educando.

O papel de sujeito que o aluno do ensino médio assume na flexibilização da grade curricular constitui-se em um importante exercício de autonomia e de responsabilidade, contribuindo para o processo de autoconhecimento que caracteriza a adolescência.

Tal compreensão fundamenta-se no papel que atribuímos à escola na formação de jovens, como o lugar privilegiado da experiência social dos adolescentes, pois é onde, na espuma da aparente rotina de todos os dias, eles reconhecem seu lugar na realidade social e tecem seus projetos existenciais. Conforme Pais (1993), o cotidiano - no caso, o cotidiano escolar -, é uma espécie de "ateliê existencial” (Certeau, 1985), onde os adolescentes provam suas potencialidades, criam novas formas de estar no mundo, novas formas de solidariedade e de representatividade social.

No início do ensino médio, a questão fundamental para os alunos, segundo Althuon (1999), é situar-se e organizar-se na dimensão tempo-es- 
paço em busca de sua própria identidade como sujeito social, participante e construtor da vida em sociedade. Assim, a experiência de fazer a opção por uma área do conhecimento e pelas disciplinas optativas que irá cursar constitui importantes instrumentos nesse processo de autoconhecimento e de protagonismo social, condição primeira do exercício da cidadania.

A reformulação curricular também objetiva ampliar a premissa de atender à especificidade e à heterogeneidade individual do educando, que é incentivado a tecer sua própria rede de conhecimentos a partir de escolhas responsáveis, fundamentadas no conhecimento de suas características pessoais e aspirações profissionais.

Com isso, o novo projeto para o ensino médio busca responder às preocupações com o futuro profissional que estão cada vez mais presentes entre os jovens que iniciam o ensino médio, segundo estudo de Pont \& Peppl (1999). Em contraposição às escolas que confundem educação com preparação para o vestibular e fazem desse nível de ensino uma corrida precoce ao mercado de trabalho, nossa proposta pedagógica convoca o educando a estabelecer relaçóes significativas com os distintos campos do conhecimento, vivenciando tanto o contato mais aprofundado com uma área do conhecimento por meio das disciplinas acessórias obrigatórias quanto a possibilidade de cursar disciplinas optativas nas outras áreas.

Diante de itinerários de vida imprevisíveis, o currículo do ensino médio visa proporcionar ao aluno oportunidades de desenvolver, de forma articulada, conhecimentos, emoçóes e atitudes que fundamentam a elaboração e a realização de um projeto próprio de vida. Partimos da compreensão de que, para enfrentar os desafios da sociedade contemporânea,

a sensibilidade, a intuição, a criatividade passam a ser atributos fundamentais para a vida em um mundo caracterizado pela fluidez e incertezas provocadas pelas aceleradas transformaçóes contemporâneas, pois neles os indivíduos são chamados a traçar o seu caminho sem poder contar com o apoio de referencias fixos, não apenas na esfera do trabalho, mas nas relações pessoais, afetivas, sexuais, sociais, culturais. (Barreto, 2002, p. 363)

Em outras palavras, nossa proposta, além da questão cognitiva, fundamenta-se na "revalorização das teorias que destacam a importância dos afetos e da criatividade no ato de aprender", pois a integração da aprendizagem "com as demais dimensões da personalidade é o desafio que as tarefas de vida na sociedade da informação e do conhecimento estão (re)pondo à educação e à escola” (Brasil, 2002, p. 72). 
Reconhece-se, portanto, a subjetividade dos alunos como orientação para a construção do currículo. A intuição, a criatividade e o prazer passam a ser pressupostos da integração dos educandos no processo de aprendizagem, visto que, conforme alertou Snyders (1988), é necessário que a alegria perpasse o cotidiano escolar, onde os jovens devem encontrar possibilidades de realizar suas aspirações no momento presente, sem postergá-las para o futuro.

\section{REFERÊNCIAS}

ALTHUON, B. O fazer cotidiano do ensino médio à luz de novo tempo. Revista de Educação AEC, Brasília, n. 113, p. 98-103, 1999.

BARRETO, E. S. de S. As novas políticas para o ensino médio no contexto da educação básica. In: ZIBAS, D. M. L.; AGUIAR, M. A. da.; BUENO, M. S. S. (Org.). O ensino médio e a reforma da educação básica. Brasília: Plano Editora, 2002. p. 353-365.

BRASIL. Parâmetros Curriculares Nacionais: ensino médio. Brasília, DF: MEC/SEMTEC, 2002.

CENTRO DE ENSINO E PESQUISA APLICADA À EDUCAÇÃO. Projeto Político-Pedagógico: versão preliminar. Goiânia: Cepae, 2002.

CERTEAU, M. A invenção do cotidiano. Petrópolis: Vozes, 1985.

CUNHA, L. A. As agências financeiras internacionais e a reforma brasileira do ensino técnico: a crítica da crítica. In: ZIBAS, D. M. L.; AGUIAR, M. A. da.; BUENO, M. S. S. (Org.). O ensino médio e a reforma da educação básica. Brasília, DF: Plano Editora, 2002. p. 103-134.

CURY, C. R. J. Políticas atuais para o ensino médio e a educação profissional em nível técnico: problemas e perspectivas. In: ZIBAS, D. M. L.; AGUIAR, M. A. da.; BUENO, M. S. S. (Org.). O ensino médio e a reforma da educação básica. Brasília, DF: Plano Editora, 2002. p. 15-32.

ETGES, N. Ciência, interdisciplinaridade e educação. In: JANTSCH, A. P.; BIANCHETTI, L. (Org.). Interdisciplinaridade: para além da filosofia do sujeito. Petrópolis: Vozes, 1995. p. 51-96.

KUENZER, A. Z. (Org.). Ensino médio: construindo uma proposta para os que vivem do trabalho. São Paulo: Cortez, 2002. 
MENEZES, L. C. Razões e elementos para uma revisão do projeto pedagógico da escola. 1999. Mimeografado.

NOGUEIRA, A. A pedagogia: uma contribuição científica para o trabalho educativo interdisciplinar. In: ; MORAES, S. (Org.). Contribuição da interdisciplinaridade: para a ciência, para a educação, para o trabalho sindical. Petrópolis: Vozes, 1994. p. 89-102.

OLIVEIRA, D. A. O ensino médio no contexto das políticas para a educação básica. In: ZIBAS, D. M. L.; AGUIAR, M. A. da.; BUENO, M. S. S. (Org.). O ensino médio e a reforma da educação básica. Brasília, DF: Plano Editora, 2002. p. 47-69.

PAIS, J. M. Nas rotas do cotidiano. Revista Critica de Ciências Sociais, Coimbra, n. 37, p. 105-115, 1993.

PONT, C.; PEPPL, R. O ensino médio na visão dos estudantes. Revista de Educação AEC, Brasília, DF, n. 113, p. 17-19, 1999.

SNYDERS, G. A alegria na escola. São Paulo: Manole, 1988.

ZIBAS, D. M. L. (Re)significando a reforma do ensino médio: o discurso oficial e os filtros institucionais. In: ; AGUIAR, M. A. da.; BUENO, M. S. S. (Org.). O ensino médio e a reforma da educação básica. Brasília, DF: Plano Editora, 2002. p. 71-92.

Recebido em: 3 jun. 2005.

Aceito em: 20 set. 2005. 